\title{
Fermentation products: immunological effects on human and animal models
}

\author{
Audrey Granier ${ }^{1}$, Olivier Goulet ${ }^{2}$ and Cyrille Hoarau ${ }^{1,3}$
}

Infant formulas have been shown to influence the development of the gut microbiota. Besides the probiotic- and prebiotic-containing formulas, fermented milk-based infant formulas offer an additional means for modulation of gut immunity and/or gut microbiota. These formulas are produced by the fermentation of cow's milk with specific lactic acid bacteria strains, followed by heat treatment; they do not contain viable bacteria or added prebiotic oligosaccharides but contain specific products resulting from the fermentation process. This review is focused on the effects of fermentation products, distinguishing them from those of living bacteria and prebiotic compounds on the immune system. Besides the possible modulation of gut microbiota composition, in vitro and in vivo studies suggest that specific fermentation products can actively participate in the establishment of immune balance and oral tolerance. Although further research is needed to confirm the clinical benefits observed in infants to better characterize the active fermentation compounds and to delineate the involved pathways, these fermented formulas appear to deserve interest.

드다. xclusive breast feeding is recommended for feeding infants from birth to 6 mo (1). Human milk provides protection against infectious diarrhea, especially rotavirus-related diarrhea, and against upper respiratory tract infections (2). Moreover, maternal milk promotes the development of a bifidobacteria-dominant intestinal microbiota. This microbiota, progressively augmented during the first weeks of life (3), is crucial in the development of the gut immune system (4) and results in protective effects against enteric pathogens and possibly against allergic diseases (5).

Conventional infant formulas have been shown to influence the development of the intestinal microbiota (6). In breast-fed infants, bifidobacteria become dominant, whereas in most standard formula-fed infants, similar amounts of Bacteroides and Bifidobacterium ( 40\% each) are found. The fecal microbiota from breast-fed infants contains Lactobacillus and Streptococcus, whereas stools from formula-fed infants often contain Staphylococcus, Escherichia coli, and Clostridia (6). Developing infant formulas that modulate the infant intestinal microbiota in promoting the development of bifidobacteria appears to be a relevant approach.

Both probiotic- and prebiotic-containing formulas have been shown to have bifidogenic effects $(7,8)$. Probiotics are "live microorganisms, which when administered in adequate amounts confer a health benefit to the host" (9). Prebiotics are nondigestible food ingredients that selectively stimulate the growth and/or activity of one or a limited number of bacteria in the gut microbiota that confer health benefits to the host (10). The clinical effects of probiotic- or prebiotic-containing infant formulas on the incidence and/or severity of gastrointestinal disorders and early childhood-onset allergic diseases have been reviewed elsewhere $(11,12)$.

Fermented milk-based infant formulas (FMBIFs) are produced by the fermentation of formula based on cow's milk with lactic acid-producing bacteria (LAB) (13), followed by heat treatment to kill viable bacteria after fermentation. These formulas do not contain the live bacteria that are present in probiotic-based infant formula, nor added (prebiotic) oligosaccharides; instead, they contain products resulting from the fermentation process, the properties of which might offer specific means to interact with the intestinal mucosa. An FMBIF based on the fermentation of cow's milk by Bifidobacterium breve and Streptococcus thermophilus has been reported to have beneficial effects in infants. A randomized, double-blind, placebo-controlled trial aimed to determine whether the size of the intestinal bifidobacterial flora can influence the immune response to poliovirus vaccination in infants (14). This study involved 30 infants, although 20 completed the study. From birth to 4 mo, 11 infants were fed FMBIF fermented from $S$. thermophilus and B. breve and 9 infants received a standard formula. Bifidobacteria were quantified monthly in infant stools. Anti-poliovirus IgA response to Pentacoq (Pasteur Mérieux Serums and Vaccines, Lyon, France; acellular pertussis, diphtheria, Haemophilus-adsorbed influenza type b conjugate,

'Dendritic Cells and Immunointervention-Transplants (CDG), François Rabelais University of Tours, Tours, France; ${ }^{2}$ Department of Pediatric Gastroenterology-Hepatology and Nutrition, Necker Children's Hospital, University of Paris, Paris, France; ${ }^{3}$ Department of Allergy and Clinical Immunology, University Hospital of Tours, Tours, France. Correspondence: Cyrille Hoarau (hoarauc@med.univ-tours.fr) 


\section{Fermentation products and immunity}

inactivated poliomyelitis, and tetanus) was assessed before and $1 \mathrm{mo}$ after the second injection. Results indicate that the fecal bifidobacterial level was significantly higher $(P<0.04)$ in the FMBIF group at 4 mo of age. Anti-poliovirus IgA titers increased after Pentacoq vaccination, but the rise was significantly higher $(P<0.02)$ in the FMBIF-fed group. Antibody titers correlated with bifidobacteria, especially with $B$. longum infantis and $B$. breve levels $(P<0.002)$. Infants who harbored $B$. longum infantis also exhibited high levels of anti-poliovirus IgA $(P<0.002)$. This study showed that anti-poliovirus response can be enhanced by an FMBIF that is able to favor intestinal bifidobacteria. Another randomized, double-blind, placebocontrolled trial (15) confirmed the interest in FMBIFs by demonstrating the upregulation of fecal secretory IgA. A randomized, double-blind, placebo-controlled trial studied the effects of an FMBIF with B. breve C50 and S. thermophilus 065 on thymus size and stool $\mathrm{pH}$ of healthy term infants (16). A total of 90 term neonates were separated into three different groups: 30 newborns were exclusively breast-fed, and the remaining 60 were randomly assigned to receive either an FMBIF or a standard formula. Evaluations were performed on the third day of life and on the first, second, third, and fourth months of life. Thymus sizes and thymus indexes were measured by using ultrasound examinations, and measurements of stool $\mathrm{pH}$, an indicator of gut flora functionality, were done at the same time. The difference in thymus indexes was statistically significant over repeated measurements among the groups. The FMBIF infants had similar thymus indexes as the breast-fed infants. The fecal $\mathrm{pH}$ of the breast-fed group was lower than the standard formula group $(P<0.05)$, whereas it was similar to that of the FMBIF group on the third postnatal day, persisting for the entire 4 mo of the study.

The randomized controlled trial performed by Thibault et al. (17) assessed the clinical effects of an FMBIF fermented formula on the incidence of acute diarrhea and its severity in healthy infants. This study involved 971 infants aged 4 to 6 mo over a period of 5 mo. They consumed daily either an FMBIF fermented with B. breve C50 and S. thermophilus $065(n=464)$ or a standard infant formula of the same nutritional composition $(n=449)$. The number and duration of acute diarrhea episodes were recorded, and the severity of the episodes was evaluated by the number of hospital admissions, the incidence of dehydration, the number of medical consultations, the number of oral rehydration solution prescriptions, and the number of formula changes. Incidence, duration of diarrheal episodes, and number of hospital admissions did not differ significantly among the groups. However, episodes were less severe in the FMBIF group because there were fewer cases of dehydration 2.5 vs. $6.1 \%(P=0.01)$, fewer medical consultations (46 vs. $56.6 \%, P=0.003)$, fewer oral rehydration solute prescriptions 41.9 vs. $51.9 \%(P=0.003)$, and fewer changes to other formulas (59.5 vs. $74.9 \%, P=0.0001$ ).

For allergy, the impact of an FMBIF was tested on the incidence of allergy-like events in 129 children at high risk of atopy, in a multicenter, randomized, double-blind, controlled study (18). Infants received an FMBIF or a standard formula from

\section{Integrated Mechanism Review}

birth until $1 \mathrm{y}$ of age, and were followed at 4,12 , and $24 \mathrm{mo}$. Skin prick tests for six foods and six aeroallergens were systematically performed. In case of potentially allergic adverse events, allergy could be further tested by skin prick tests, patch tests, and quantification of specific IgEs. If cow's milk allergy was suspected, an oral challenge could also be performed. The use of FMBIF milk did not alter the proportion of cow's milk allergy, but decreased the proportion of positive skin prick tests to cow's milk (1.7 vs. $12.5 \%, P=0.03)$, and the incidence of digestive ( 39 vs. $63 \%, P=0.01$ ), and respiratory potentially allergic events ( 7 vs. $21 \%, P=0.03$ at $12 \mathrm{mo}$ ).

Although such FMBIFs are currently available to an increasing number of infants, the preclinical data regarding the mechanisms elicited by fermentation products have not been reviewed until now. This review thus aims to emphasize the basic concept of fermentation and the effect of fermentation products on gut microbiota and immune function.

\section{WHAT ARE FERMENTED PRODUCTS?}

Fermentation has been used since ancient times, primarily to enhance food preservation, and to aid development of specific foods and beverages. Besides these technological advantages, fermentation processes increase the nutritional interest of numerous foods and enhance bioavailability of nutrients. These links between fermentation, nutrition, and health have been popularized with products such as fermented milks. Yogurt, the most documented example, is defined as a coagulated milk product that results from fermentation of lactose, the milk sugar, into lactic acid by Lactobacillus bulgaricus and S. thermophilus. The transformation of lactose into lactic acid is the most significant phenomenon, but fermented milks also contain a wide range of potentially active components, still not comprehensively characterized. Triglyceride lipolysis is negligible because of the absence of lipase in LAB, but the weak proteolytic activity of LAB determines the lysis of 1 to $2 \%$ of the casein and liberation of amino acids and peptides (19). In parallel, bacterial enzymes can metabolize milk carbohydrates into a wide variety of oligosaccharides, some of which have prebiotic properties (20). FMBIFs also contain several types of growth factors and hormones and a range of components originating from the $\mathrm{LAB}$ themselves, from the cell walls (peptidoglycans, lipoteichoic acid), or from the cytoplasmic content (bacterial DNA) (21). These compounds, usually present in small amounts, are thought to exhibit specific properties, mostly in the area of immunostimulation (21). Some fermentation products are metabolized by the microorganisms that have produced them, whereas others accumulate in the FMBIF and may exhibit functional properties (22).

Whereas lactic acid production is a feature common to all $\mathrm{LAB}$, the production of other compounds depends on the bacterial strains and on the conditions of the fermentation process, including the medium that is fermented. The LAB strains most often used to ferment milk are $S$. thermophilus, usually in association with bifidobacteria, such as $B$. breve $\mathrm{C} 50, B$. lactislongum, and B. animalis, or with lactobacilli such as L. acidophilus, L. rhamnosus, L. johnsonii, and $L$. casei. These different 


\section{Integrated Mechanism Review}

species produce different fermentation products, which may help to explain the different results sometimes encountered.

In most fermented milk, the LAB remain alive in the product and may transiently interact with endogenous intestinal microbiota and with the cells of the intestinal wall. These products may also contain fermentation products, but they are not usually considered relevant because the health benefit is supposed to be given by the living bacteria, and no attempt is made to optimize the fermentation products. This is not the case in FMBIFs in which fermentation conditions are specifically designed, via the choice of the LAB strains and a thorough control of technological processes (23).

Because of the variety of strains and complexity of the fermentation substrate, the exact composition and molecular structure of fermentation products are not exhaustively known. Molecular identification of compounds should be a research objective in this new area because identification is necessary for a detailed understanding of the effects and ultimately for their maximization. One of the most studied heat-treated fermented formulas is obtained in a two-step fermentation; the S. thermophilus 065 strain, selected for its high $\beta$-galactosidase production, ferments a lactose solution and produces galacto-oligosaccharides by transgalactosylation of lactose, with $\sim 30 \%$ of newly produced di-, tri-, and tetrasaccharides (24). A separate fermentation of cow's milk by $B$. breve C50 leads to a specific carbohydrate pattern, different from the one obtained with other $B$. breve strains; the fermented milk also contains specific peptides (European patent 1615657, Gervais-Danone, Levallois Perret, France). Both fermented substrates are then mixed and heat treated.

With such a process, FMBIF contains fermentation products but also whole dead cells and fragments of heat-inactivated LAB, which may elicit effects on gut mucosa or microbiota. This is why, in preclinical studies investigating the mechanisms and components involved, the FMBIFs are submitted to further ultracentrifugation and ultrafiltration to specifically study products that are between 100 and $300 \mathrm{kDa}$, the expected molecular range of fermentation products.

\section{FERMENTATION PRODUCTS ARE MODULATORS OF THE} INTESTINAL MICROBIOTA

The effects of the products issued from LAB fermentation on the composition of the intestinal microbiota have been studied in healthy adults who, for $1 \mathrm{wk}$, received either a cell-free concentrated whey from B. breve C50-fermented milk (whey group) or a diluted milk (control group) (25). The total counts of bifidobacteria were higher in the feces of the whey group as compared with control group. Because the gut microbiota of healthy adults is known to be quite stable for a given subject, these results suggest that the components produced during fermentation have a strong potential to modulate the composition of the gut microbiota. Similar results have been obtained in human adults fed an oligosaccharide obtained from lactose fermented by B. bifidum NCIMB 41171, confirming that LAB can be used to produce prebiotic compounds (26).

Studies have compared gut microbiota composition and metabolism during the colonization period between newborn

\section{Granier et al.}

infants receiving from birth either a standard non-fermented formula or FMBIF (14). Feces were sampled monthly for 4 mo and infants fed the fermented formula had a higher mean proportion of bifidobacteria with fewer adult-like species. These infants were more frequently colonized by $B$. longum infantis and $B$. breve, species mostly encountered during breast feeding and associated to an enhanced barrier function and immune priming (27). Indeed, adequate maturation of the infant immune system is known to be connected to gut colonization by microbiota (28) and especially to some specific Bifidobacterium species, including the ones found in breast-fed infants (29).

\section{FERMENTATION PRODUCTS MODULATE THE IMMUNE SYSTEM}

Live commensal microbiota is essential for the development of the gut's immune system and for tolerance to food antigens $(30,31)$. The interactions between bacteria and the immune system are only partially understood, as are those induced by specific metabolites produced after the fermentation process. Dendritic cells (DCs) play a key role in this interaction as antigen-presenting cells. These initially immature cells reside in nonlymphoid organs, notably in the gut mucosa, where they capture and process antigens. In the presence of "danger" signals, DCs migrate into the T-cell areas of lymphoid organs and mature to acquire the ability to present antigens to naive $\mathrm{T}$ cells and to induce specific immunogenic responses. DCs also have the capacity to induce negative regulation of immune responses, by the generation of regulatory T cells (32).

The balance between "immunogenic" or "tolerogenic" DCs seems to be partially dependent on the DC type, the levels of costimulatory molecule expression, the cytokine production profile, and the survival capacity of the DCs $(33,34)$. The specific DC functionalities result from the integration of different intracellular signals induced by the microenvironment, particularly from pathogen-associated molecular patterns from specific bacteria (35). To sense the microenvironment, DCs express receptors as Toll-like receptors (TLRs) that recognize pathogen-associated molecular patterns (36). TLR engagement can induce a wide variety of signal transduction pathways, as mitogen-activated protein kinases or phosphatidylinositol 3-kinase, to regulate the nature, magnitude, and duration of the immune responses, and thus the capacity to induce "immunogenic" or "tolerogenic" DCs. The different human TLRs recognize a broad spectrum of specific highly conserved microbial structures. The transduction pathway depends on the bacteria strain and thus on the TLR engaged, which could explain the different effects observed on DC functionality (37). Because of these properties and their capacity to elicit various responses to different stimuli, DCs represent a potential target for fermentation products, through which they can trigger a range of immunomodulatory properties.

\section{IN VITRO STUDIES}

Several studies have shown that bacteria can affect the maturation and cytokine secretion profile of DCs depending on the bacterial strain $(38,39)$. In particular, LAB can interact with monocyte-derived DCs to modulate their properties 


\section{Fermentation products and immunity}

$(32,40-42)$. This effect is probably linked to the bacterial characteristics, including cell wall components, cytoplasmic compounds, and DNA fragments, whereas the natural fermentation process occurring in the gut might produce active components as well. Active bacterial components from B. breve C50 can cross an intestinal monolayer of epithelial cells and modulate cytokine production (43).

Our team has recently studied in vitro the effects of media fermented with different strains of B. breve (A. Granier et al., unpublished data). In these fermented media, bacteria were separated from the supernatant via centrifugation and ultrafiltration. Unlike other strains, the supernatant from $B$. breve C50 strain culture (BbC50sn) induced maturation (Figure 1a) and activation of human DCs (Figure 1b-e), but only after fermentation of a milk whey-based medium (Figure 2). BbC50sn induced a specific interleukin-10 (IL-10)-rich cytokine profile (Figure $1 \mathrm{~b}$ ) and prolonged DC survival via a TLR2 pathway (44). IL-10 is involved in inducing immune tolerance and controlling the contact duration between DCs and T cells, a key point in this induction that depends on DC survival (45). The antiapoptotic BbC50sn signal surpasses the proapoptotic effect

\section{Integrated Mechanism Review}

of lipopolysaccharide on DCs. Furthermore, the induction of potential "tolerogenic" DC properties by fermentation products has been confirmed in human DCs treated with BbC50sn, which could induce $\mathrm{CD} 4$ and $\mathrm{CD} 8$ regulatory $\mathrm{T}$ cells.

The maturation process of DCs induced by BbC50sn appears to involve nuclear factor- $\kappa \mathrm{B}(44)$ and to differentially activate mitogen-activated protein kinase, glycogen synthase kinase-3, and phosphatidylinositol 3-kinase pathways (46). These results give new insights on the fine-tuned balance inducible by specific fermentation products.

\section{ANIMAL STUDIES}

Several in vivo studies confirm the immunomodulatory properties of fermentation products (47). Infant formula containing fermentation products can alter immune responses: the systemic responses, especially Th1 and IL-10, were increased in ovalbumin-immunized mice fed FMBIF as compared with control mice. The development of oral tolerance was not affected in mice fed FMBIF, whereas the local production of interferon- $\gamma$, IL-12p40, and IL-10 was significantly increased (48).

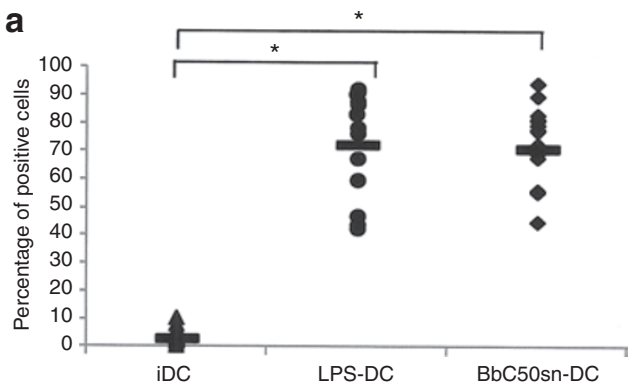

b

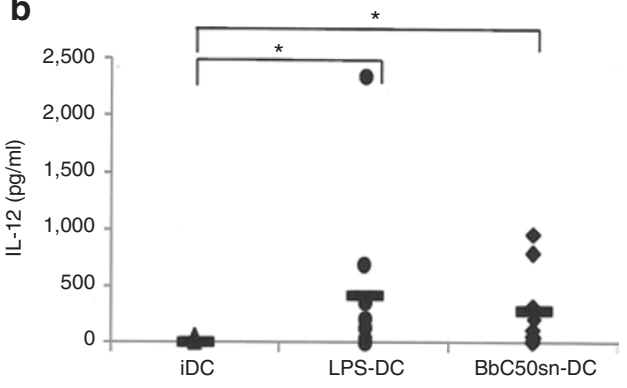

d

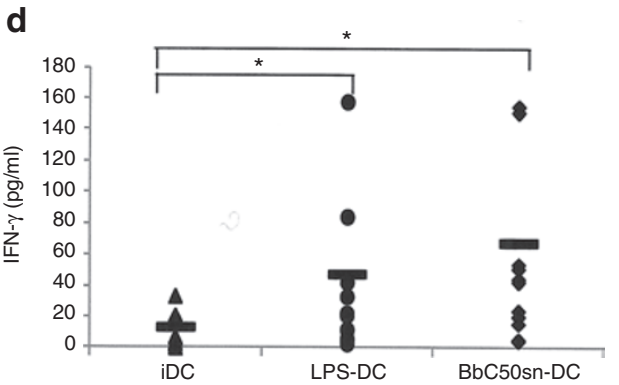

c

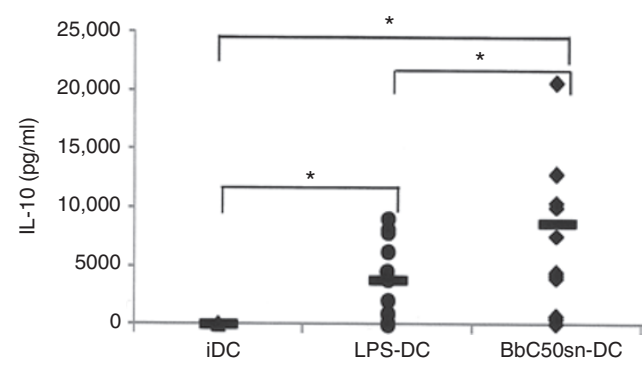

e

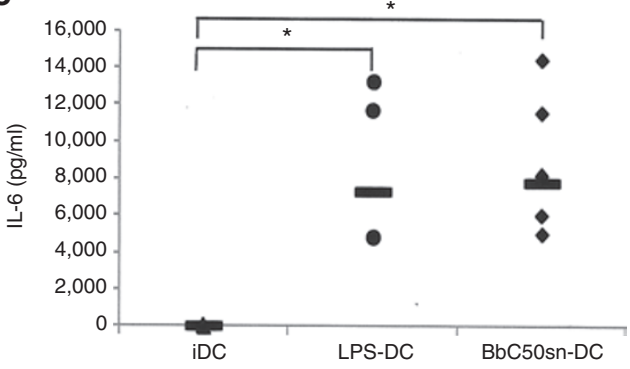

Figure 1. Phenotype and activation of dendritic cells. (a) Dendritic cell (DC) phenotype. Staining of markers CD80, CD83, CD86, and CD25 was analyzed by cytometry for immature DCs (iDCs) and DCs treated with $50 \mathrm{ng} / \mathrm{ml}$ of LPS (LPS-DCs) or with $50 \mathrm{\mu g} / \mathrm{ml}$ of BbC50sn (BbC50sn-DCs). Secretion of (b) IL-12, (c) IL-10, (d) IFN- - , and (e) IL-6 by iDCs, LPS-DCs, and BbC50sn-DCs, assessed by ELISA. Each point represents a donor, and bars represent means. For statistical data, the Wilcoxon test was used; ${ }^{*} P<0.05$. BbC50sn and LPS induced maturation, and IL-10 secretion was higher for BbC50sn-DCs. ELISA, enzymelinked immunosorbent assay; IFN, interferon; IL, interleukin; LPS, lipopolysaccharide. 
a
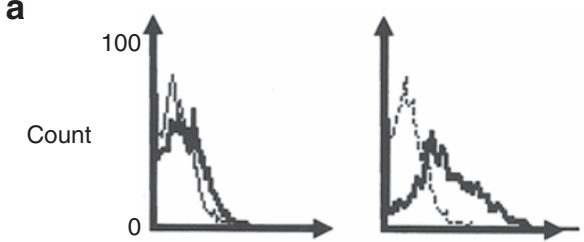

b

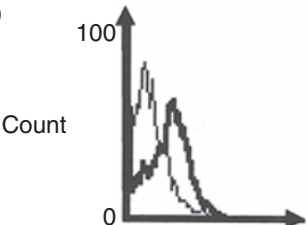

C

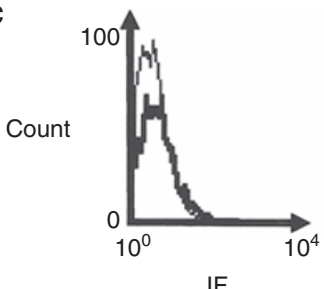

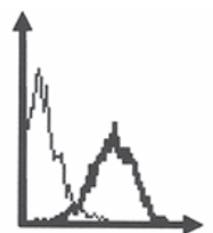

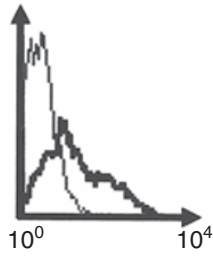

IF
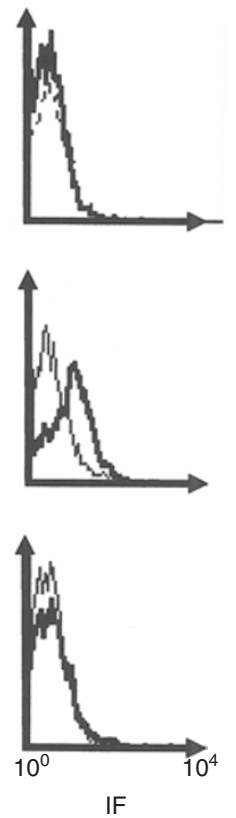

Figure 2. Dendritic cell (DC) phenotype analysis by cytometry. CD83, CD86, and HLA-DR were studied on DCs in the presence of (a) casein-hydrolysate in the presence of $\mathrm{BbC50}$, (b) whey hydrolysate fermented by $\mathrm{BbC50}$, or (c) whey hydrolysate without $\mathrm{BbC50}$. The $x$-axes represent the intensity of fluorescence (IF) and the $y$-axes the cell counts. Bold histograms represent specific staining of the indicated cell-surface markers, and thin histograms correspond to isotype controls: DC maturation (upregulation of CD83, CD86, and HLA-DR) is observed only when the fermentation process occurs with whey hydrolysate medium. HLA, human histocompatibility leukocyte antigen.

Similarly, nonbacterial fractions of milk fermented by Lactobacillus helveticus, containing specific peptides and oligosaccharides, were shown to modulate mucosal immunity. IgA production was increased in the gut of mice fed the bacteria-free fermented milk product. Cytokine production, particularly IL-10, was affected in mucosal cells (49). In a mouse model, exopolysaccharide produced by Lactobacillus kefiranofaciens could modulate immune responses (50). Furthermore, in mice infected with Salmonella enterididis, the survival of mice fed with a nonbacterial fraction of fermented milk was enhanced as compared with the control group (51).

In a model of starved mice, the reconstitution of the immune system was studied after renutrition with milk, probiotic fermented milk, or a bacteria-free supernatant of probiotic fermented milk. Probiotic fermented milk and probiotic fermented milk supernatant increased bifidobacteria in the intestinal microbiota and the number of $\operatorname{IgA}^{+}$cells, macrophages, and, especially in the supernatant, the number of DCs (52)

These results suggest that specific products of fermentation, independently of living bacteria, can modulate mucosal immune responses. These products could induce Th1 or regulatory $\mathrm{T}$ cells, and thus could actively participate in the establishment of immune balance and tolerance in infants.

\section{DISCUSSION}

The critical role of infant feeding in gut colonization and subsequent maturation of the mucosal immune system is widely recognized, as is the recommendation for breast feeding to reach optimal immune function. When infant formulas are to be used, several options exist that aim at getting closer to the function of human milk in establishing balanced gut immunity and ultimately contributing to prevent allergic or infectious diseases. In addition to probiotic- or prebiotic-containing formulas, fermentation products, whose production involves specific bacterial strains, appear as an additional route. They may act through modulation of the gut microbiota, but also through direct interactions with the mucosal immune system, promoting immune balance by inducing regulatory $\mathrm{T}$ cells.

To discuss the advantages that fermentation products could bring in addition to probiotic- or prebiotic-containing infant formulas, one would need direct comparison among the three concepts. Unfortunately, the clinical studies are set up in different ways (i.e., food matrix, infant population, intake duration, and clinical outcomes), making the comparison difficult. Clinical trials in infants have suggested a beneficial role of fermented products in formulas. However, these trials investigate the effects of heat-treated fermented milks that may still contain bacterial fragments, possibly involved in the observed effects (53). High-quality randomized controlled trials are required to distinguish the immune effects of fermentation products from those elicited by bacterial cell walls and to definitely confirm the specific immune-modulatory properties suggested in preclinical experiments. Nevertheless, FMBIFs have specific features that are scientifically and clinically relevant.

FMBIFs do not contain living organisms and are therefore stored easily. In addition, and even though the risk of bacterial translocation appears limited to fragile infant populations, this risk does not exist in FMBIFs. One single clinical trial reported that some newborns consuming a formula containing a high amount of heat-inactivated L. rhamnosus GG exhibited symptoms of gut discomfort (54). In the currently marketed FMBIFs, dead bacterial bodies come from bacterial species that have not been associated with any adverse effects.

Fermentation products do not depend on in vivo fermentation processes, which can vary widely according to subjects and conditions, as may be the case for prebiotic-containing formulas. Probiotics in infant formulas may act via interactions with the mucosa (55), whose nature and magnitude will depend on the nature, number, and physiological status of the LAB strain actually reaching the mucosa. This variability could contribute to the variance in effects, which is sometimes observed in randomized controlled trials with prebiotics or probiotics, and could be reduced when fermented products are directly provided, because their activity will not depend on further steps within the gut. Fermentation products can be controlled through precise monitoring of the technological process, which will ensure reproducibility. However, research should be focused on the molecular characterization of fermentation products and bacterial strains. The target immune 


\section{Fermentation products and immunity}

cells and the target population should be defined through better insights into the mechanisms involved.

In clinical practice, the beneficial effects of the three types of infant formula (i.e., prebiotic, probiotic, and fermented) may be close or even similar, but their mechanisms of action exhibit some differences. A better understanding of their action at the gut and mucosal levels may contribute to a better knowledge of mucosal immune maturation and to the necessary discussion regarding the use of infant formulas oriented to immunomodulation. Fermented products and their presence in infant formulas thus provide relevant additions in the landscape of infant feeding.

\section{STATEMENT OF FINANCIAL SUPPORT}

Some research projects carried out in the teams of O.G. and C.H. have been supported by Danone Baby Nutrition.

\section{REFERENCES}

1. Cattaneo A, Burmaz T, Arendt M, et al. Protection, promotion and support of breast-feeding in Europe: progress from 2002 to 2007. Public Health Nutr 2009;13:751-9.

2. Howie PW, Forsyth JS, Ogston SA, Clark A, Florey CD. Protective effect of breast feeding against infection. BMJ 1990;300:11-6.

3. Palmer C, Bik EM, DiGiulio DB, Relman DA, Brown PO. Development of the human infant intestinal microbiota. PLoS Biol 2007;5:e177.

4. Sudo N, Sawamura S, Tanaka K, Aiba Y, Kubo C, Koga Y. The requirement of intestinal bacterial flora for the development of an IgE production system fully susceptible to oral tolerance induction. J Immunol 1997;159:1739-45.

5. Kalliomäki M, Salminen S, Arvilommi H, Kero P, Koskinen P, Isolauri E. Probiotics in primary prevention of atopic disease: a randomized placebocontrolled trial. Lancet 2001;357:1076-9.

6. Harmsen HJ, Wildeboer-Veloo AC, Raangs GC, et al. Analysis of intestinal flora development in breast-fed and formula-fed infants by using molecular identification and detection methods. J Pediatr Gastroenterol Nutr 2000;30:61-7.

7. Macfarlane GT, Steed H, Macfarlane S. Bacterial metabolism and healthrelated effects of galacto-oligosaccharides and other prebiotics. J Appl Microbiol 2008;104:305-44.

8. Rao S, Srinivasjois R, Patole S. Prebiotic supplementation in full-term neonates: a systematic review of randomized controlled trials. Arch Pediatr Adolesc Med 2009;163:755-64.

9. Joint FAO/WHO Working Group Report on Drafting Guidelines for the Evaluation of Probiotics in Food. 2002. London, Ontario, Canada. (ftp:// ftp.fao.org/es/esn/food/wgreport2.pdf.)

10. Roberfroid M, Gibson GR, Hoyles L, et al. Prebiotic effects: metabolic and health benefits. Br J Nutr 2010;104:Suppl 2:S1-63.

11. Braegger C, Chmielewska A, Decsi T, et al.; ESPGHAN Committee on Nutrition. Supplementation of infant formula with probiotics and/or prebiotics: a systematic review and comment by the ESPGHAN committee on nutrition. J Pediatr Gastroenterol Nutr 2011;52:238-50.

12. Thomas DW, Greer FR; American Academy of Pediatrics Committee on Nutrition; American Academy of Pediatrics Section on Gastroenterology, Hepatology, and Nutrition. Probiotics and prebiotics in pediatrics. Pediatrics 2010;126:1217-31.

13. Chouraqui JP, Grathwohl D, Labaune JM, et al. Assessment of the safety, tolerance, and protective effect against diarrhea of infant formulas containing mixtures of probiotics or probiotics and prebiotics in a randomized controlled trial. Am J Clin Nutr 2008;87:1365-73.

14. Mullié C, Yazourh A, Thibault H, et al. Increased poliovirus-specific intestinal antibody response coincides with promotion of Bifidobacterium longum-infantis and Bifidobacterium breve in infants: a randomized, double-blind, placebo-controlled trial. Pediatr Res 2004;56:791-5.

15. Campeotto F, Suau A, Kapel N, et al. A fermented formula in pre-term infants: clinical tolerance, gut microbiota, down-regulation of fecal calprotectin and upregulation of fecal secretory IgA. Br J Nutr 2011; 105:1843-51.

\section{Integrated Mechanism Review}

16. Indrio F, Ladisa G, Mautone A, Montagna O. Effect of a fermented formula on thymus size and stool $\mathrm{pH}$ in healthy term infants. Pediatr Res 2007;62:98-100.

17. Thibault H, Aubert-Jacquin C, Goulet O. Effects of long-term consumption of a fermented infant formula (with Bifidobacterium breve c50 and Streptococcus thermophilus 065) on acute diarrhea in healthy infants. J Pediatr Gastroenterol Nutr 2004;39:147-52.

18. Morisset M, Aubert-Jacquin C, Soulaines P, Moneret-Vautrin DA, Dupont C. A non-hydrolyzed, fermented milk formula reduces digestive and respiratory events in infants at high risk of allergy. Eur J Clin Nutr 2011;65:175-83.

19. Halasz A. Lactic acid bacteria. In: Lasztity R, ed. Food Quality and Standards. Vol III in Encyclopedia of Life Support Systems. Oxford, UK: Eolss Publishers, 2009:70-82.

20. Mahoney RR. Galactosyl-oligosaccharide formation during lactose hydrolysis: a review. Food Chem 1998;63:147-54.

21. Meydani SN, Ha WK. Immunologic effects of yogurt. Am J Clin Nutr 2000;71:861-72.

22. Hayes M, Stanton C, Fitzgerald GF, Ross RP. Putting microbes to work: dairy fermentation, cell factories and bioactive peptides. Part II: bioactive peptide functions. Biotechnol J 2007;2:435-49.

23. Blareau J, Romond M, Romond C, Lecroix F, Gontier C. Method for the production of an immunostimulant milk product and uses thereof. Patent US 7,410,653 B1 (2008). (http://www.google.com/patents/US7410653.)

24. Perrin V, Fenet B, Praly JP, Lecroix F, Ta CD. Identification and synthesis of a trisaccharide produced from lactose by transgalactosylation. Carbohydr Res 2000;325:202-10.

25. Romond MB, Ais A, Guillemot F, Bounouader R, Cortot A, Romond C. Cell-free whey from milk fermented with Bifidobacterium breve C50 used to modify the colonic microflora of healthy subjects. J Dairy Sci 1998;81:1229-35.

26. Depeint F, Tzortzis G, Vulevic J, I’anson K, Gibson GR. Prebiotic evaluation of a novel galactooligosaccharide mixture produced by the enzymatic activity of Bifidobacterium bifidum NCIMB 41171, in healthy humans: a randomized, double-blind, crossover, placebo-controlled intervention study. Am J Clin Nutr 2008;87:785-91.

27. Ewaschuk JB, Diaz H, Meddings L, et al. Secreted bioactive factors from Bifidobacterium infantis enhance epithelial cell barrier function. Am J Physiol Gastrointest Liver Physiol 2008;295:G1025-34.

28. Calder PC, Krauss-Etschmann S, de Jong EC, et al. Early nutrition and immunity - progress and perspectives. Br J Nutr 2006;96:774-90.

29. Sela DA, Mills DA. Nursing our microbiota: molecular linkages between bifidobacteria and milk oligosaccharides. Trends Microbiol 2010;18: 298-307.

30. Brandtzaeg PE. Current understanding of gastrointestinal immunoregulation and its relation to food allergy. Ann N Y Acad Sci 2002;964: $13-45$.

31. Rhee KJ, Sethupathi P, Driks A, Lanning DK, Knight KL. Role of commensal bacteria in development of gut-associated lymphoid tissues and preimmune antibody repertoire. J Immunol 2004;172:1118-24.

32. Smits HH, de Jong EC, Wierenga EA, Kapsenberg ML. Different faces of regulatory DCs in homeostasis and immunity. Trends Immunol 2005;26:123-9.

33. Pulendran B, Banchereau J, Maraskovsky E, Maliszewski C. Modulating the immune response with dendritic cells and their growth factors. Trends Immunol 2001;22:41-7.

34. Pulendran B, Kumar P, Cutler CW, Mohamadzadeh M, Van Dyke T, Banchereau J. Lipopolysaccharides from distinct pathogens induce different classes of immune responses in vivo. J Immunol 2001;167:5067-76.

35. Kapsenberg ML. Dendritic-cell control of pathogen-driven T-cell polarization. Nat Rev Immunol 2003;3:984-93.

36. Akira S, Hemmi H. Recognition of pathogen-associated molecular patterns by TLR family. Immunol Lett 2003;85:85-95.

37. Qi H, Denning TL, Soong L. Differential induction of interleukin-10 and interleukin-12 in dendritic cells by microbial toll-like receptor activators and skewing of T-cell cytokine profiles. Infect Immun 2003;71: 3337-42. 


\section{Integrated Mechanism Review}

38. Christensen HR, Frøkiaer H, Pestka JJ. Lactobacilli differentially modulate expression of cytokines and maturation surface markers in murine dendritic cells. J Immunol 2002;168:171-8.

39. Hart AL, Lammers K, Brigidi P, et al. Modulation of human dendritic cell phenotype and function by probiotic bacteria. Gut 2004;53:1602-9.

40. Smits HH, Engering A, van der Kleij D, et al. Selective probiotic bacteria induce IL-10-producing regulatory $\mathrm{T}$ cells in vitro by modulating dendritic cell function through dendritic cell-specific intercellular adhesion molecule 3-grabbing nonintegrin. J Allergy Clin Immunol 2005;115:1260-7.

41. Foligne B, Nutten S, Grangette C, et al. Correlation between in vitro and in vivo immunomodulatory properties of lactic acid bacteria. World J Gastroenterol 2007;13:236-43.

42. Foligne B, Zoumpopoulou G, Dewulf J, et al. A key role of dendritic cells in probiotic functionality. PLoS ONE 2007;2:e313.

43. Ménard S, Candalh C, Bambou JC, Terpend K, Cerf-Bensussan N, Heyman M. Lactic acid bacteria secrete metabolites retaining anti-inflammatory properties after intestinal transport. Gut 2004;53:821-8.

44. Hoarau C, Lagaraine C, Martin L, Velge-Roussel F, Lebranchu Y. Supernatant of Bifidobacterium breve induces dendritic cell maturation, activation, and survival through a Toll-like receptor 2 pathway. J Allergy Clin Immunol 2006;117:696-702.

45. Moser M. Balancing life and death. Nat Immunol 2004;5:559-60.

46. Hoarau C, Martin L, Faugaret D, et al. Supernatant from bifidobacterium differentially modulates transduction signaling pathways for biological functions of human dendritic cells. PLoS ONE 2008;3:e2753.

47. de Moreno de LeBlanc A, Chaves S, Carmuega E, Weill R, Antoine J, Perdigon G. Effect of long-term continuous consumption of fermented milk

\section{Granier et al.}

containing probiotic bacteria on mucosal immunity and the activity of peritoneal macrophages. Immunobiology 2008;213:97-108.

48. Ménard S, Candalh C, Ben Ahmed M, et al. Stimulation of immunity without alteration of oral tolerance in mice fed with heat-treated fermented infant formula. J Pediatr Gastroenterol Nutr 2006;43:451-8.

49. Vinderola G, Matar C, Palacios J, Perdigón G. Mucosal immunomodulation by the non-bacterial fraction of milk fermented by Lactobacillus helveticus R389. Int J Food Microbiol 2007;115:180-6.

50. Vinderola G, Perdigón G, Duarte J, Farnworth E, Matar C. Effects of the oral administration of the exopolysaccharide produced by Lactobacillus kefiranofaciens on the gut mucosal immunity. Cytokine 2006;36: 254-60.

51. Vinderola G, Matar C, Perdigón G. Milk fermented by Lactobacillus helveticus $\mathrm{R} 389$ and its non-bacterial fraction confer enhanced protection against Salmonella enteritidis serovar Typhimurium infection in mice. Immunobiology 2007;212:107-18.

52. Maldonado Galdeano C, Novotny Núñez I, de Moreno de LeBlanc A, Carmuega E, Weill R, Perdigón G. Impact of a probiotic fermented milk in the gut ecosystem and in the systemic immunity using a non-severe protein-energy-malnutrition model in mice. BMC Gastroenterol 2011;11:64.

53. Lebeer S, Vanderleyden J, De Keersmaecker SC. Host interactions of probiotic bacterial surface molecules: comparison with commensals and pathogens. Nat Rev Microbiol 2010;8:171-84.

54. Kirjavainen PV, Salminen SJ, Isolauri E. Probiotic bacteria in the management of atopic disease: underscoring the importance of viability. J Pediatr Gastroenterol Nutr 2003;36:223-7.

55. Mennigen R, Bruewer M. Effect of probiotics on intestinal barrier function. Ann NY Acad Sci 2009;1165:183-9. 